Article

\title{
Holistic-comprehensive approaches to improve nutritional status of children under five years
}

\author{
Febri Endra Budi Setyawan, ${ }^{1}$ Retno Lestari² \\ ${ }^{1}$ Faculty of Medicine, Universitas Muhammadiyah Malang; ${ }^{2}$ School of Nursing, Faculty of Medicine, Universitas \\ Brawijaya, Malang, Indonesia
}

\begin{abstract}
Background: Malnutrition has been identified as the leading cause of illness and death in almost half of children under 5 years. Hence, to prevent the impact of malnutrition on physical and psychological development, family physicians need to explore new approaches in the health care delivery models that go beyond the scope of practice. A holistic-comprehensive approach will help the physicians develop a more thorough assessment of nutritional status. This study aims to determine factors associated with the nutritional status of children under five years using holistic-comprehensive approaches.

Design and Methods: A case-control design was implemented, with emphasis on the identification of cases and control groups; 48 children confirmed malnutrition cases and 48 control without malnutrition were recruited from a Community Integrated Health Center in East Java, Indonesia. The characteristics of agent, host and environment between groups were compared and analyzed using correlation coefficients, odds ratio, logistic regression analysis, and Structural Equation Modeling-Partial Least Square (SEM-PLS).

Results: The SEM-PLS results showed that environmental factors have a greater influence on nutritional status ( $\mathrm{t}$-value $>1.96$ ), compared to the host factors. Furthermore, environmental factors having significant associations with nutritional status were poor socioeconomic status, low maternal educational level and not having exclusive breastfeeding. Also, the results of correlation coefficients and OR showed that birth weight $(p=0.000, O R=33$ ) and socioeconomic status $(\mathrm{p}=0.000, \mathrm{OR}=22.3)$ had strong correlations with nutritional status.

Conclusions: Holistic-comprehensive approaches can be used as new ways to determine factors that may be associated with nutritional status of children under 5 years of age.
\end{abstract}

\section{Introduction}

Malnutrition was identified as the leading cause of illness and death in almost half of children under five years old worldwide. ${ }^{1,2}$ Global data from UNICEF, WHO and World Bank Group showed that about 144.0 million children under 5 years in 2019 suffered stunting, and 38.3 million were living with overweight. ${ }^{3}$ This condition reflects an increase in associated risk factors of nutritional issues, ranging from agent, host, and environmental factors. Meanwhile, studies showed that maternal educational level, nutrition before and during pregnancy, antenatal care, exclusive breastfeeding, complementary foods practices, and socioeconomic status have been recognized as environmental factors that can affect nutritional status. ${ }^{4-7}$

Also, recent studies suggested that the presence of children's age, gender differences, history of birth complications, congenital abnormalities, low birth weight, immunization history, and history of infectious diseases can influence the risk of childhood nutritional problems, which are known as host factors. ${ }^{5,8-12}$ In the case of malnutrition, agent factors as the cause of diseases can include nutritional status. ${ }^{13}$ Therefore, understanding these factors may affect family physicians' judgments to develop strategies in clinical assessment or disease prevention that are more effective than others.

The consequences of malnutrition among children under five years old have been well documented which include global developmental delay in many areas, such as delay in physical growth, cognitive and social developmental delay, and increased risk of contracting infectious diseases. ${ }^{14}$ However, there are widespread barriers that might be particularly challenging for Indonesian families of low socioeconomic status living in poverty as they have to manage many demanding jobs and require more efforts to pay the health insurance, as well as ensure their families health. ${ }^{15}$ Therefore, family physicians need to explore new approaches in the health care delivery models that go beyond the scope of practice and improve quality of life in low income families.

Efforts to improve health care delivery for clinical assessment of malnutrition should be made to help physicians design interventions that prevent children infectious diseases. Meanwhile, the epidemiological triangle of agent-host-environment model has been commonly used to describe epidemiology and disease control in populations. It can also be adapted for understanding factors that are related to the nutritional issues during childhood. More importantly, assessing epidemiological evidence should be used to achieve consensus about intervention priorities for nutritional issues. Hence, holistic-comprehensive approaches are needed to

Significance for public health

Malnutrition among children under five years old causes a global developmental delay in many areas, namely physical, cognitive, and social, which is linked to increased risk of infectious diseases. The epidemiologic triangle is a model for explaining the causal factors of malnutrition, which include the health status of children under five years and other family health factors. This paper showed factors associated with malnutrition cases of children under five years of age using holistic-comprehensive approaches based on epidemiological triangle model. 
help physicians develop a more thorough assessment of nutritional status among children under five years. The holistic-comprehensive approaches refer to the process of using whole aspects of biological factors, psychological conditions, and social characteristics (cultural and social issues) to continually gather information on children nutritional status, in order to provide feedback to improve disease prevention. ${ }^{16,17}$ Therefore, this study aims to determine factors associated with nutritional status of children under five years using holistic-comprehensive approaches. This study would be useful in the development of practices in family physicians to unravel malnutrition issues and also contribute to the literatures by providing facts on the determinants of nutritional status.

\section{Design and Methods}

A case-control study was designed to determine factors associated with nutritional status, with an emphasis on the identification of cases and control groups. 48 children confirmed malnutrition cases (using total sampling) and 48 control (using systematic random sampling) were recruited from a Community Integrated Health Center in East Java. All the respondents were registered in the selected health center as community outpatients, and gave their informed consent before they participated in the study. Ethical approval was obtained from the Ethics Committee of Faculty of Medicine, Universitas Muhammadiyah Malang. Also, data were collected using specially developed questionnaires, which covered all the cases data and control groups. In this study, the characteristics of agent, host and environment between groups were compared. Furthermore, cases and control groups were compared in terms of the following variables: nutritional status, children characteristics (age, sex, history of birth complications, congenital abnormalities, birth weight, immunization history, history of infectious diseases in the past 3 months), and environmental characteristics (socioeconomic status, cultural influence, maternal education, exclusive breastfeeding, complementary feeding practices). This study developed a framework of holistic-comprehensive approaches to improve nutritional status of children under five years (Figure 1). Briefly, according to epidemiological triangle, factors that influence nutritional status include: (1) host factors (X1): age (X1.1), sex (X1.2), birth complications history (X1.3), congenital abnormalities (X1.4), birth weight (X1.5), immunization history (X1.6), and history of infectious disease (X1.7). (2) Environmental factors (X2): socioeconomic status (X2.1), cultural influence (X2.2), maternal education (X2.3), exclusive breastfeeding (X2.4), and complementary feeding practices (X2.5). (3) Agent factors (Y): children nutritional status.

In this study, correlation coefficients, odds ratio (OR), and $95 \%$ confidence intervals $(\mathrm{CI})$ were assessed and variables whose values were statistically significant $(\mathrm{p}<0.005)$ were inputted into a logistical regression using SPSS Version 20.0. Furthermore, data were subsequently analyzed using Structural Equation ModelingPartial Least Square (SEM-PLS) to identify factors that have a greater influence on nutritional status.

\section{Results and Discussions}

Table 1 showed the characteristics of host-agent factors, which illustrated that poor nutritional status was found to be higher in children aged 0-35 months (30.2\%), birth weight less than 2500 grams $(34.4 \%)$, and history of contracting infectious diseases in the past 3 months (34.4\%), even though they had complete immunization status (32.2\%). In addition, Table 2 showed the characteristics of environmental-agent factors, which demonstrated that poor nutritional status was higher in families with poor socioeconomic status (39.6\%), low maternal educational level (45.8\%), and not having exclusive breastfeeding (38.5\%).

Table 3 showed the results of correlation coefficients and odds ratio between host-environmental factors. It described that birth weight $(\mathrm{p}=0.000, \mathrm{OR}=33)$ and socioeconomic status $(\mathrm{p}=0.000$, $\mathrm{OR}=22.3$ ) had strong correlations with nutritional status. Meanwhile, history of infectious diseases in the past 3 months $(\mathrm{p}=0.000, \mathrm{OR}=6.6)$ and maternal educational level $(\mathrm{p}=0.000$, $\mathrm{OR}=22$ ) had moderate correlations with nutritional status. Furthermore, Table 4 showed the results of logistic regression analysis. It described several factors associated with nutritional status among children under 5 years old: birth weight (X1.5), immunization history (X1.6), history of infectious disease (X1.7), socioeconomic status (X2.1), maternal education (X2.3), exclusive breastfeeding (X2.4), and complementary feeding practices (X2.5). The SEM-PLS results (Figure 2) showed that environmental factors have a greater influence on nutritional status (t-value $>1.96$ ), compared to the host factors. Meanwhile,

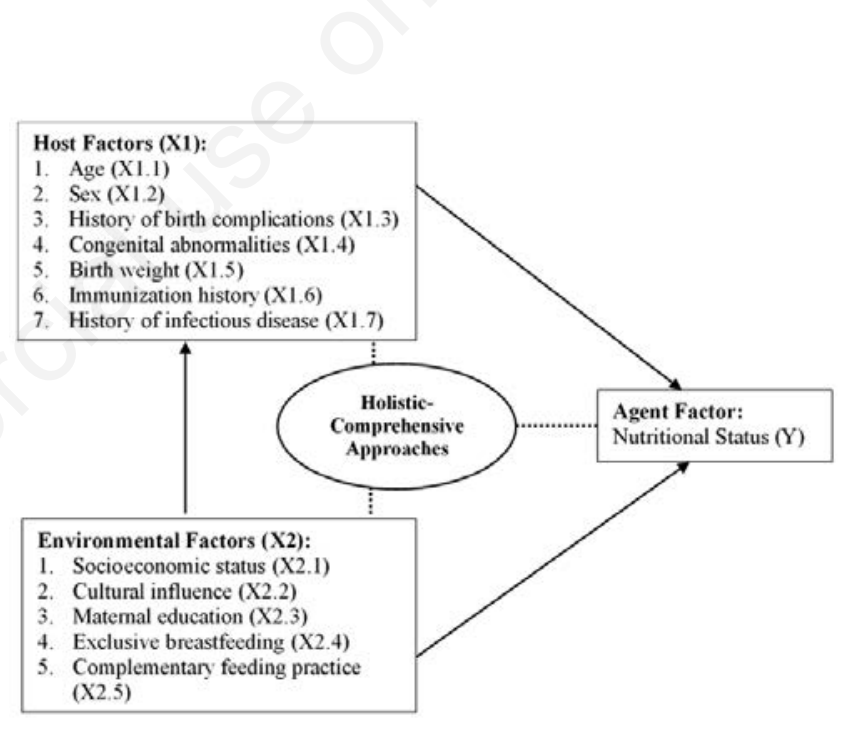

Figure 1. Framework of holistic-comprehensive approaches to improve nutritional status of children under five years of age.

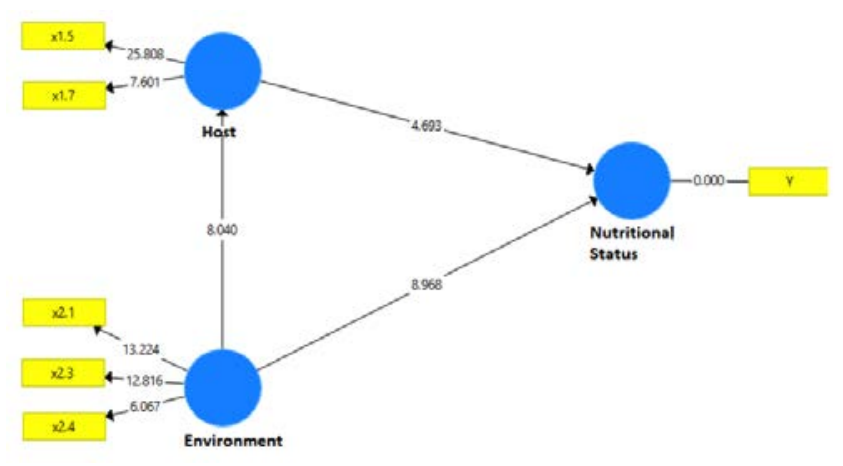

Figure 2. Structural Equation Modeling of holistic-comprehensive approaches to improve nutritional status of children under five years of age. 
Table 1. Characteristics of host-agent factors.

\begin{tabular}{|c|c|c|c|c|}
\hline \multirow[t]{2}{*}{ Characteristics } & \multirow[t]{2}{*}{ Category } & \multicolumn{2}{|c|}{ Nutritional Status } & \multirow[t]{2}{*}{ Total } \\
\hline & & Poor & Normal & \\
\hline Age (months) & $0-35$ & $29(30.2 \%)$ & $31(32.3 \%)$ & $60(62.5 \%)$ \\
\hline \multirow{2}{*}{ Sex } & & $25(960 \%)$ & $24(2500 \%$ & \\
\hline & Male & $23(24.0 \%)$ & $24(25.0 \%)$ & $47(49.0 \%)$ \\
\hline \multirow[t]{2}{*}{ History of birth complications } & Yes & $11(11.5 \%)$ & $12(12.5 \%)$ & $23(24.0 \%)$ \\
\hline & No & $37(38.5 \%)$ & $36(37.5 \%)$ & $73(76.0 \%)$ \\
\hline \multirow{2}{*}{ Congenital abnormalities } & Yes & $3(3.1 \%)$ & $3(3.1 \%)$ & $6(6.3 \%)$ \\
\hline & No & $45(46.9 \%)$ & $45(46.9 \%)$ & $90(93.8 \%)$ \\
\hline \multirow{2}{*}{ Birth weight (grams) } & $<2500$ & 33 (34.4\%) & $3(3.1 \%)$ & $36(37.5 \%)$ \\
\hline & $\geq 2500$ & $15(15.6 \%)$ & $45(46.9 \%)$ & $60(62.5 \%)$ \\
\hline \multirow{2}{*}{ Immunization history } & Incomplete & 17 (17.7\%) & $7(7.3 \%)$ & $24(25.0 \%)$ \\
\hline & Complete & $31(32.3 \%)$ & $41(42.7 \%)$ & $72(75.0 \%)$ \\
\hline \multirow[t]{2}{*}{ History of infectious disease } & Yes & $33(34.4 \%)$ & $12(12.5 \%)$ & $45(46.9 \%)$ \\
\hline & No & $15(15.6 \%)$ & $36(37.5 \%)$ & $51(53.1 \%)$ \\
\hline
\end{tabular}

Table 2. Characteristics of environmental-agent factors.

\begin{tabular}{|c|c|c|c|c|}
\hline Characteristics & Category & Nut & atus & Total \\
\hline & & Poor & Normal & \\
\hline Socioeconomic status & $\begin{array}{l}\text { Poor } \\
\text { Good }\end{array}$ & $\begin{array}{l}38(39.6 \%) \\
10(10.4 \%)\end{array}$ & $\begin{array}{c}7(7.3 \%) \\
41(42.7 \%)\end{array}$ & $\begin{array}{l}45(46.9 \%) \\
51(53.1 \%)\end{array}$ \\
\hline Cultural influence & $\begin{array}{l}\text { Yes } \\
\text { No }\end{array}$ & $\begin{array}{c}6(6.3 \%) \\
42(43.8 \%)\end{array}$ & $\begin{array}{c}8(8.3 \%) \\
40(41.7 \%)\end{array}$ & $\begin{array}{l}14(14.6 \%) \\
82(85.4 \%)\end{array}$ \\
\hline Maternal education & $\begin{array}{l}\text { Low education } \\
\text { Medium-High education }\end{array}$ & $\begin{array}{c}44(45.8 \%) \\
4(4.2 \%)\end{array}$ & $\begin{array}{l}16(16.7 \%) \\
32(33.3 \%)\end{array}$ & $\begin{array}{l}60(62.5 \%) \\
36(37.5 \%)\end{array}$ \\
\hline Exclusive breastfeeding & $\begin{array}{l}\text { No } \\
\text { Yes }\end{array}$ & $\begin{array}{l}37(38.5 \%) \\
11(11.5 \%)\end{array}$ & $\begin{array}{l}18(18.8 \%) \\
30(31.3 \%)\end{array}$ & $\begin{array}{l}55(57.3 \%) \\
41(42.7 \%)\end{array}$ \\
\hline Complementary feeding practice & $\begin{array}{l}\text { No } \\
\text { Yes }\end{array}$ & $\begin{array}{l}35(36.5 \%) \\
13(13.5 \%)\end{array}$ & $\begin{array}{l}18(18.8 \%) \\
30(31.3 \%)\end{array}$ & $\begin{array}{l}53(55.2 \%) \\
43(44.8 \%)\end{array}$ \\
\hline
\end{tabular}

Table 3. Correlation coefficients and odds ratio between host-environmental factors.

\begin{tabular}{|c|c|c|c|c|}
\hline Characteristics & Sig. & Coefficient correlation & Interpretation & Odds ratio \\
\hline Age & 0.833 & - & No correlations & - \\
\hline Sex & 1.000 & - & No correlations & - \\
\hline History of birth complications & 1.000 & - & No correlations & - \\
\hline Congenital abnormalities & 0.661 & - & No correlations & - \\
\hline Birth weight & 0.000 & 0.625 & Strong correlation & 33 \\
\hline Immunization history & 0.034 & 0.058 & Correlation very weak & 3.2 \\
\hline History of infectious disease & 0.000 & 0.438 & Medium correlation & 6.6 \\
\hline Socioeconomic status & 0.000 & 0.646 & Strong correlation & 22.3 \\
\hline Cultural influence & 0.772 & - & No correlations & - \\
\hline Maternal education & 0.000 & 0.583 & Medium correlation & 22 \\
\hline Exclusive breastfeeding & 0.000 & 0.396 & Weak correlation & 5.6 \\
\hline Complementary feeding practice & 0.001 & 0.354 & Weak correlation & 4.5 \\
\hline
\end{tabular}

Table 4. Results of logistic regression analysis.

\begin{tabular}{lll} 
Characteristics & Value & Sig. \\
Birth weight (X1.5) & 3.237 & 0.027 \\
History of immunization (X1.6) & 1.783 & 0.142 \\
\hline History of infectious disease (X1.7) & 1.886 & 0.172 \\
Socioeconomic status (X2.1) & 3.719 & 0.003 \\
\hline Maternal education (X2.3) & 4.131 & 0.011 \\
Exclusive breastfeeding (X2.4) & 2.256 & 0.069 \\
\hline Complementary feeding practice (X2.5) & 2.314 & 0.071 \\
Constanta & -28.558 & 0.000 \\
\hline
\end{tabular}


environmental factors that have significant associations with nutritional status were poor socioeconomic status, low maternal educational level, and not having exclusive breastfeeding.

The results showed that the use of holistic-comprehensive approaches to determine risk factors for nutritional status among children under five years of age was adequate. These approaches provided specific answers to study questions about epidemiological triangle in children nutritional status (the interaction of agenthost-environment factors), and it can be extended to develop strategic intervention to prevent malnutrition. Furthermore, these approaches are quite feasible and can be routinely included in the assessment, planning, and intervention phase of public health program in a Community Integrated Health Center in East Java.

Holistic-comprehensive approaches assess biopsychosocial aspects of nutritional issues among children under 5 years old. In fact, previous study demonstrated that this approach had a moderate correlation with children nutritional status $(\mathrm{r}=0.463)$. This approach not only help address nutritional issues that shape children health and development, but also promote effective strategies to improve childhood nutrition. ${ }^{18}$

Malnutrition cases are complex and can take many forms, including under- and over-nutrition. The underlying causes of malnutrition presented in this study apply specific factors based on epidemiological triangle. The interaction of agent and host factors is important to determine whether or not the causative agents invade the human host. Furthermore, this study showed that poor nutritional status was found to be higher in children aged 0-35 months $(30.2 \%)$, birth weight less than 2500 grams $(34.4 \%)$, and history of infectious diseases in the past 3 months (34.4\%), even though they had complete immunization status (32.2\%). In addition, the prevalence of chronic malnutrition in Indonesia is generally high, hence it is important to carefully find the causes.

Also, environmental factors can include biopsychosocial aspects that influence nutritional status. This study found that poor nutritional status was higher in families with low socioeconomic status (39.6\%), low maternal educational level (45.8\%), and not having exclusive breastfeeding (38.5\%). Aryastami et al. stated that there were factors related to stunting in Indonesia, such as low birth weight, male gender, history of previous illness and poor socioeconomic status. However, low birth weight was identified as the main factor that cause stunting. ${ }^{19}$ Also, poor nutritional status among infant and toddler imposes a greater burden in low socioeconomic community. Lack of nutrients and adequate health care can affect children to suffer from infectious diseases. ${ }^{20-23}$ Furthermore, exclusive breastfeeding, adequate complementary feeding practices, maternal education and psychological factors have important role in malnutrition prevention. Also, mothers who experience stress can affect their quality of breastfeeding, therefore it will impact children health and nutrition. ${ }^{24-27}$

The results of logistic regression analysis described several factors associated with nutritional status: birth weight (X1.5), immunization history (X1.6), history of infectious disease (X1.7), socioeconomic status (X2.1), maternal education (X2.3), exclusive breastfeeding (X2.4), and complementary feeding practices $(\mathrm{X} 2.5)$. Birth weight $(\mathrm{p}=0.000, \mathrm{OR}=33)$ and socioeconomic status $(p=0.000, O R=22.3)$ had strong correlations with nutritional status. This means that the odds of birth weight effects on nutritional status was 33 times greater, compared to socioeconomic status of only 22.3 times. Meanwhile, history of infectious diseases in the past 3 months $(\mathrm{p}=0.000, \mathrm{OR}=6.6)$ and maternal educational level $(\mathrm{p}=0.000, \mathrm{OR}=22)$ had moderate correlations with nutritional status. Also, studies showed that history of infectious diseases, maternal education or knowledge on children nutrition, birth interval, and types of health delivery were other factors related to environmental factors that cause children malnutrition. ${ }^{28-33}$

The SEM-PLS results (Figure 2) showed that environmental factors have a greater influence on nutritional status (t-value $>1.96$ ), compared to the host factors. Also, environmental factors with significant associations with nutritional status were poor socioeconomic status, low maternal educational level, and not having exclusive breastfeeding. This study identified factors that influence nutritional status among children under five years old using epidemiological triangle including agent (nutritional status) and host factors (birth weight, and history of infectious diseases in the past 3 months), as well as environmental factors (socioeconomic status, maternal education, and breastfeeding). It can be understood that malnutrition is such a complex condition when it comes to poor families, therefore family physicians need to address this issue using holistic-comprehensive approaches. Meanwhile, the population at the most vulnerable states are young children aged 035 months. These children need food security and social protection incentives from the government in order to benefit from micronutrients, and prevent the incidence of malnutrition.

\section{Conclusions}

There are no easy solutions to address nutritional issues among children under five years old, but using holistic-comprehensive approaches can make a significant difference. Furthermore, family physicians can play a role in improving the assessment of children nutritional status, and enhancing the health care of those families living in poverty. In conclusion, holistic-comprehensive approaches can help physicians determine all factors associated with nutritional status of children under five years old. 
Correspondence: Febri Endra Budi Setyawan, Faculty of Medicine, Universitas Muhammadiyah Malang, Jl. Bendungan Sutami 188A Malang Jawa Timur 65145, Indonesia.

Tel.+62.34155149 - Fax: +62.341582060. E-mail: febri@umm.ac.id

Key words: Holistic-comprehensive approaches; nutritional status; children.

Acknowledgment: The authors would like to specially appreciate the Faculty of Medicine, Universitas Muhammadiyah Malang, Indonesia for their support and guidance during this study.

Contributions: All authors contributed equally to the design and implementation of this study, the results analysis, as well as writing of the manuscript.

Conflict of interests: The authors declare no conflicts of interest. The content of the manuscript have been seen and agreed. Also, it was certified that the submission is original and is not under review at any other publication. This manuscript reflects the authors' own study and analysis in a truthful and complete manner. All respondents gave their informed consent before participation.

Funding: This study was supported by Faculty of Medicine, Universitas Muhammadiyah Malang.

Ethical approval: Obtained from the Ethics Committee of Faculty of Medicine, Universitas Muhammadiyah, Malang, Indonesia (No. E.5.a/147/KEPK-UMM/II/2020).

Conference presentation: Part of this study was presented at the $1^{\text {st }}$ International Nursing and Health Sciences Symposium, November $13^{\text {th }}$ to $15^{\text {th }} 2020$, Brawijaya University, Malang, Indonesia.

Received for publication: 14 January 2021.

Accepted for publication: 18 March 2021.

oCopyright: the Author(s), 2021

Licensee PAGEPress, Italy

Journal of Public Health Research 2021;10:2183

doi:10.4081/jphr.2021.2183

This work is licensed under a Creative Commons Attribution NonCommercial 4.0 License (CC BY-NC 4.0).

\section{References}

1. WHO. Children: improving survival and well-being. Geneva: World Health Organization; 2020 [cited 2020 Oct 20]. Available from: https://www.who.int/news-room/factsheets/detail/children-reducing-mortality

2. India State-Level Disease Burden Initiative Malnutrition Collaborators. The burden of child and maternal malnutrition and trends in its indicators in the states of India: the Global Burden of Disease Study 1990-2017. Lancet Child Adolesc Health 2019;3:855-70.

3. UNICEF, WHO, International Bank for Reconstruction and Development/The World Bank. Levels and trends in child malnutrition: Key Findings of the 2020 Edition of the joint child malnutrition estimates. Geneva: World Health Organization; 2020.

4. Titaley CR, Ariawan I, Hapsari D, et al. Determinants of the stunting of children under two years old in Indonesia: A multilevel analysis of the 2013 Indonesia Basic Health Survey.
Nutrients 2019;11:1106.

5. Rahman MS, Howlader T, Masud MS, et al. Association of low-birth weight with malnutrition in children under five years in Bangladesh: Do mother's education, socio-economic status, and birth interval matter? PLoS One 2016;11:e0157814.

6. Anwar S, Nasreen S, Batool Z, et al. Maternal education and child nutritional status in Bangladesh: Evidence from demographic and health survey data. Pak J Life Soc Sci 2013;11:7784.

7. Abuya BA, Ciera J, Kimani-Murage E. Effect of mother's education on child's nutritional status in the slums of Nairobi. BMC Pediatr 2012;12:80.

8. Abdulahi A, Shab-Bidar S, Rezaei S, et al. Nutritional status of under five children in Ethiopia: A systematic review and metaanalysis. Ethiop J Health Sci 2017;27:175-88.

9. Hubschman LE. Malnutrition in congenital heart disease. ICAN Infant Child Adolesc Nutrn 2013;5:170-6.

10. Farhadi S, Ovchinnikov RS. The relationship between nutrition and infectious diseases: A review. Biomed Biotechnol Res J 2018;2:168-72.

11. Khan S, Zaheer S, Safdar NF. Determinants of stunting, underweight and wasting among children $<5$ years of age: evidence from 2012-2013 Pakistan demographic and health survey. BMC Public Health 2019;19:358.

12. Prendergast AJ. Malnutrition and vaccination in developing countries. Philos Trans R Soc Lond B Biol Sc. 2015;370:20140141.

13. Johnson-Walker YJ, Kaneene JB. Epidemiology: Science as a tool to inform one health policy. In Herrmann JA, JohnsonWalker YJ, editors. Beyond one health: From recognition to results. Hoboken: Wiley; 2018. p. 3-30.

14. Dea P, Chattopadhyay N. Effects of malnutrition on child development: Evidence from a backward district of India. Clin Epidemiol Glob Health 2019;7:439-445.

15. Hanandita W, Tampubolon G. The double burden of malnutrition in Indonesia: Social determinants and geographical variations. SSM Popul Health 2015;1:16-25.

16. Supriyanto S, Ernawaty E, Setyawan FEB, et al. Enhancing family medicine practice in developing countries through a holistic-comprehensive care model: A review. Indian J Public Health Res Dev 2020;11:774-8.

17. Setyawan FEB, Supriyanto S, Ernawaty E, et al. Developing a holistic-comprehensive assessment model: Factors contributing to personal protective equipment compliance among Indonesian cement workers. Indian J Occup Environ Med 2020;24:19-24.

18. Setyawan FEB, Widiadi CE. The effect of holistic comprehensive health service approach through family functions on optimizing the nutrition status of junior high school students. Jurnal Saintika Medika 2020;16:1-13.

19. Aryastami NK, Shankar A, Kusumawardani N, et al. Low birth weight was the most dominant predictor associated with stunting among children aged 12-23 months in Indonesia. BMC Nutrition 2017;3:16.

20. Solomons NW, Vossenaar M. Towards appropriate feeding to prevent malnutrition in infants and toddlers. Eur J Clin Nutr 2018;72:1274-81.

21. Urke HB, Bull T, Mittelmark MB. Socioeconomic status and chronic child malnutrition: wealth and maternal education matter more in the Peruvian Andes than nationally. Nutr Res 2011;31:741-7.

22. Akombi BJ, Agho KE, Renzaho AM, et al. Trends in socioeconomic inequalities in child undernutrition: Evidence from 
Nigeria Demographic and Health Survey (2003-2013). PLoS One 2019;14:e0211883.

23. Dekker LH, Mora-Plazas M, Marín C, et al. Stunting associated with poor socioeconomic and maternal nutrition status and respiratory morbidity in Colombian schoolchildren. Food Nutr Bull 2010;31:242-50.

24. Mohseni M, Aryankhesal A, Kalantari N. Prevalence of malnutrition among Iran's under five-year-old children and the related factors: A systematic review and meta-analysis. Iran J Pediatr 2018;28:e9189.

25. Krol KM, Grossmann T. Psychological effects of breastfeeding on children and mothers. Bundesgesundheitsblatt Gesundheitsforschung Gesundheitsschutz 2018;61:977-85.

26. Webb HJ. Maternal self-rated health and psychological distress predict early feeding difficulties: Results from the longitudinal study of Australian children. Int J Eat Disord 2018;51:1312-21.

27. Nguyen PH, Sanghvi T, Kim SS, et al. Factors influencing maternal nutrition practices in a large scale maternal, newborn and child health program in Bangladesh. PLoS One 2017; 12:e0179873.
28. Dessie ZB, Fentie M, Abebe Z, et al. Maternal characteristics and nutritional status among 6-59months of children in Ethiopia: further analysis of demographic and health survey. BMC Pediatrics 2019;19:83.

29. Javid N, Pu C. Maternal stature, maternal education and child growth in Pakistan: a cross-sectional study. AIMS Public Health 2020;7:380-92.

30. Ghosh S. Factors responsible for childhood malnutrition: A review of the literature. Curr Res Nutr Food Sci 2020;8:36070.

31. Zhang P, Wu J, Xun N. Role of maternal nutrition in the health outcomes of mothers and their children: A retrospective analysis. Med Sci Monit 2019;25:4430-7.

32. Workicho A, Belachew T, Argaw A, et al. Maternal nutritional status mediates the association between maternal age and birth outcomes. Maternal Child Nutr 2020;16:e13015.

33. Huynh G, Huynh QHN, Nguyen NHT, et al. Malnutrition among 6-59-month-old children at District 2 Hospital, Ho Chi Minh City, Vietnam: Prevalence and associated factors. BioMed Res Int 2019;2019:6921312. 